\title{
Long-term Follow-up of Spinal Cord Injury Patients with Vesicoureteral Reflux
}

\author{
S. Lamid, MD \\ Milwaukee Veterans Administration Medical Center and Louisiana State Uni- \\ versity Medical Center, New Orleans, Louisiana, USA
}

\begin{abstract}
Summary
The medical records of 32 spinal cord injury patients with 43 vesicoureteral refluxes admitted to our hospital from 1970 to 1982 were retrospectively reviewed. These patients were followed yearly with pyelograms together with cystograms or cystourethrograms. Many of these individuals were on an indwelling Foley catheter at the time reflux was detected, indicating that free urinary drainage such as a Foley catheter did not prevent reflux formation. Further, the majority of refluxes developed 1-2 years post-injury, and some disappeared spontaneously without causing any damage to the urinary tract. However, the indwelling Foley catheter was ineffective for reflux treatment because in the long run it did not prevent progression of vesicoureteral reflux and did not protect the refluxing kidney from damage. We also noticed that the incidence of reflux was statistically higher in patients with complete spinal lesion than in those with incomplete neurological dysfunction. This incidence was also higher in individuals with an upper motor neuron lesion.
\end{abstract}

Key words: Vesicoureteral reflux; Spinal cord injury.

It is well known that vesicoureteral (VU) reflux is one of the complications of spinal cord injury (SCI) (Fellows and Silver, 1976; VanArsdalen and Hackler, 1983; Hackler, 1982). The etiology of VU reflux in adult SCI is not well understood and therefore the treatment is usually empirical. Such treatments include reflux surgery, external sphincterotomy, and clean intermittent catheterisation (VanArsdalen and Hackler, 1983; Kass et al., 1981). In addition, many patients with VU reflux are treated with an indwelling Foley catheter (Fellows and Silver, 1976; VanArsdalen and Hackler, 1983). However, Fellows and Silver (1976) reported that during a long term follow-up, a permanent urethral catheter does not protect the refluxing kidney from subsequent damage. It is our impression that the indwelling Foley catheter does not prevent reflux formation in SCI patients and indeed causes a progressive worsening of VU 
refluxes, resulting in damage to the upper urinary tract. This paper describes the fate of $43 \mathrm{VU}$ refluxes in 32 SCI patients that we followed on indwelling Foley catheter, intermittent catheterisation and suprapubic catheter over a 12 year period.

\section{Materials and methods}

Patients: The medical records of SCI patients with VU reflux admitted to the Milwaukee Veterans Administration Medical Center from 1970 to 1982 were reviewed extensively. All patients admitted were newly injured individuals. Thirty-two patients (13 quadriplegics and 19 paraplegics) with ages ranging from 19 to 66 years (mean 29.72) years, S.E.M. \pm 1.93 ) had ureteral reflux on radiological examination (Table $I$ ). All patients were males, and it is assumed that these individuals had no reflux before the spinal injury.

Table I Level of injury and completeness/ incompleteness in spinal lesion (number of patients)

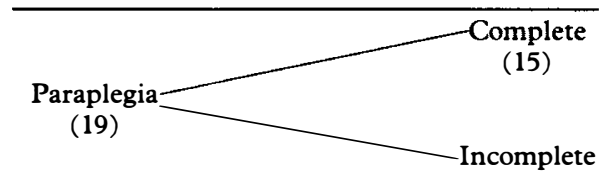

(4)

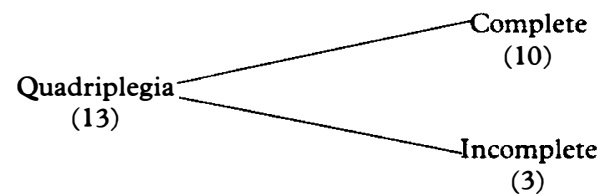

\section{Radiological examination}

These patients had an annual pyelogram together with a cystogram or cystouretherogram during the follow-up period. Interpretation of the radiological examinations was made together with the staff radiologist.

\section{Laboratory examination}

During the annual follow-up the following laboratory tests were performed: serum creatinine, blood urea nitrogen, urinalysis, and urine culture.

\section{Criteria for reflux}

We used the International Reflux Committee Study Criteria to grade the reflux (International Reflux Study Committee, 1981). Grade I: ureter only. Grade II: ureter, pelvis and calices. No dilatation. Grade III: mild or moderate dilatation and/or tortuosity of ureter and mild or moderate dilatation of renal pelvis. Grade IV: moderate dilatation and/or tortuosity of ureter and moderate dilatation 
of renal pelvis. Grade V: Gross dilatation and tortuosity of ureter. Reflux was recorded as transient (presented on one occasion and then disappeared), the same grade (stable) or progressive (worsened).

\section{Criteria for balanced bladder}

Residual urine was less than $100 \mathrm{cc}$ with bladder capacity of more than $150 \mathrm{cc}$ (VanArsdalen and Hackler, 1983).

\section{Urinary drainage}

The type of urinary drainage at the time of detection of VU reflux and during the follow-up period was recorded. Any operation procedure to relieve reflux was also noted.

\section{Results}

All 32 patients with 43 VU refluxes were still alive during the 12 years followup period. Their blood urea nitrogen and serum creatinine levels were consist-

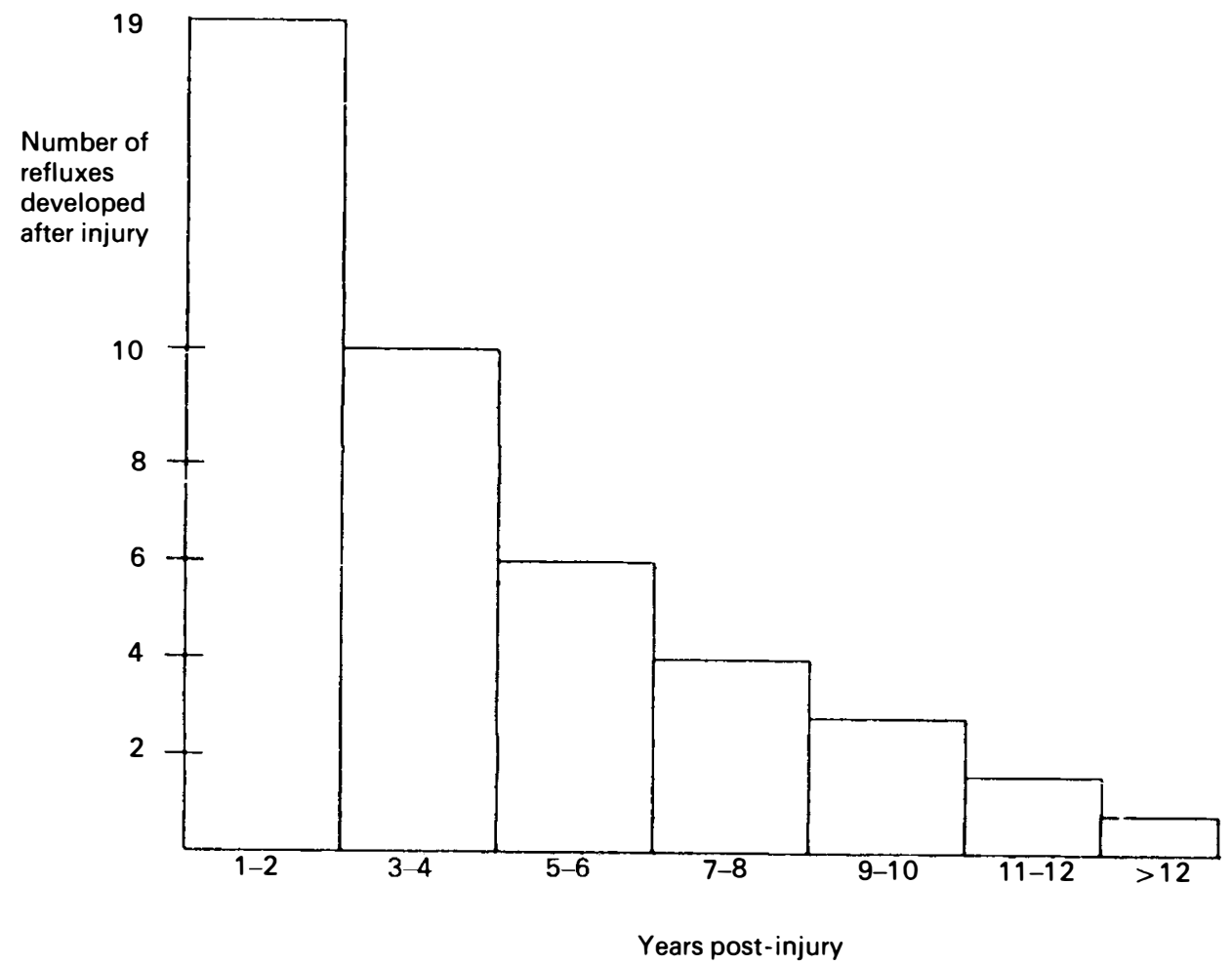

Figure Relationship between reflux formation and years post-injury 
ently within normal limits during that time. Eighteen refluxes developed during the 2 post-injury years (Figure). One reflux developed 14 years later after the injury.

\section{Urinary drainage}

Twenty-four patients were on indwelling Foley catheter drainage at the time VU reflux was detected (Table II). These patients remained on a Foley catheter

Table II Methods of urinary drainage

\begin{tabular}{lcc}
\hline & $\begin{array}{c}\text { At the time } \\
\text { reflux was detected } \\
\text { (number of patients) }\end{array}$ & $\begin{array}{c}\text { At last follow-up } \\
\text { (number of patients) }\end{array}$ \\
\hline Foley catheter & 24 & 27 \\
External condom catheter & 7 & 4 \\
Suprapubic catheter & 1 & 1 \\
\hline
\end{tabular}

during the follow-up period. One patient had a suprapubic cystostomy tube and used the same urinary drainage after the detection of reflux. Seven patients with external condom catheters had reflux which was treated according to the following methods: (1) an indwelling Foley catheter was inserted into the bladder of 3 patients; (2) one patient who had detrusor-sphincter dyssynergia was treated by external sphincterotomy; (3) three other patients was treated with intermittent catheterisation without sphincterotomy, because they did not have dyssynergia.

\section{Follow-up of Foley catheter group (Table III)}

There were 27 patients with $38 \mathrm{VU}$ refluxes in this group. We followed up these patients from 1 year to more than 12 years. All individuals in the 1 year follow-up subgroup had normal upper urinary tract and their refluxes disappeared spontaneously (transient) or remained in the same grade I (stable). After 2-3 years some of the refluxes got worse (grade III) and resulted in caliectasis of the refluxing kidneys. Several refluxes of the 4-5 years subgroup progressed to grade IV, resulting in caliectasis and a small kidney. After 6 years of follow-up the number of refluxes increased and progressed to grade IV which caused caliectasis. However, all patients had normal serum creatinine and blood urea nitrogen during the follow-up period. In addition, all individuals had asymptomatic bacteriuria which was not treated. However, many of them who had symptomatic episodes of urinary tract infection were treated with antibiotics.

\section{Follow-up of intermittent catheterisation group}

This group consists of 4 patients with 4 refluxes (Table IV). One patient had an external sphincterotomy, but the follow-up period was only 1 year. The other 3 
SPINAL CORD INJURY PATIENTS WITH VESICOURETERAL REFLUX
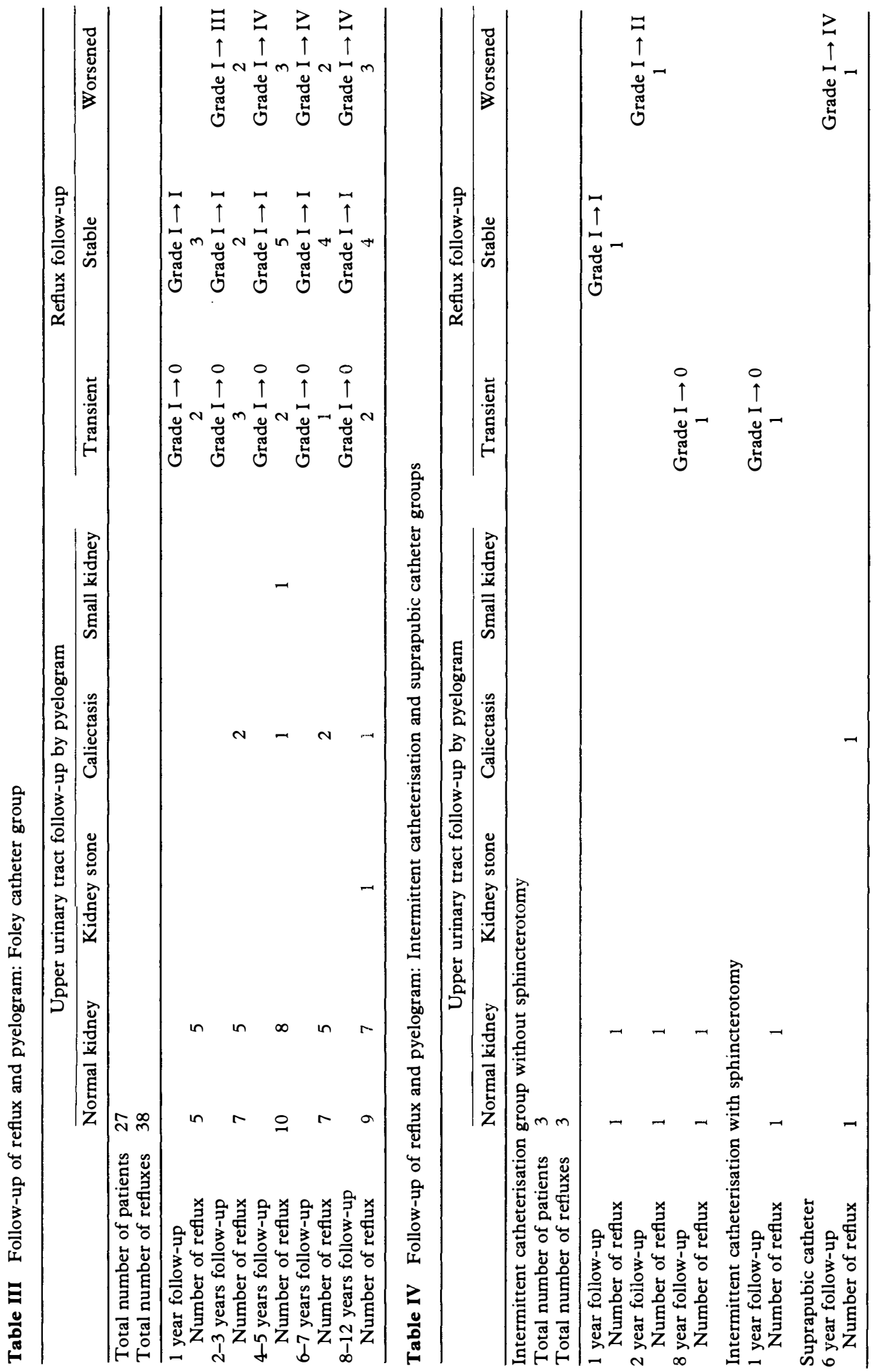
patients did not have a sphincterotomy. One of these patients had an 8-year follow-up period; however, he had a transient reflux with no kidney damage. All subjects were on an intermittent catheterisation program. They had a balanced bladder and a normal upper urinary tract.

\section{Suprapubic catheter group}

We had one patient with a suprapubic cystostomy tube (Table IV). He was followed for 6 years and VU reflux progressed to grade IV, resulting in kidney damage with caliectasis.

\section{Completeness of spinal lesion and $V U$ reflux}

Twenty-five patients $(78.1 \%$ ) with complete spinal lesions had reflux. Whereas, reflux formation occurred in only 7 individuals $(21.9 \%)$ with incomplete neurological dysfunction. We used the National SCI Data Base (Fine et al., 1985) as comparison and the chi-square $\left(\chi^{2}\right)$ for statistical analysis (Woolf, 1968). We found that the difference between completeness and incompleteness of the spinal lesion in regards to reflux formation was statistically significant $(p<0.005)$. In addition, $62.5 \%$ of our patients who had reflux had an upper motor neuron lesion.

\section{Level of spinal injury and $V U$ reflux}

Thirteen quadriplegics $(40.6 \%)$ and 19 paraplegics $(59.4 \%)$ had reflux. Using the National SCI-Data Base (Fine et al., 1985) for comparison, the difference in reflux formation between these 2 groups of patients with different level of injury was not significant.

\section{Discussion}

We studied retrospectively 32 SCI patients with $43 \mathrm{VU}$ refluxes. The majority of these patients had an indwelling Foley catheter at the time reflux was detected. Therefore, it is our impression that a free urinary drainage such as Foley catheter did not protect against reflux formation. Further, it is difficult to ascertain whether these patients had a hyperreflexic bladder, since they did not have cystometrograms carried out before and after VU reflux was detected. Therefore, a prospective urodynamic study should be carried out to elucidate the mechanism of reflux formation. The majority of refluxes developed during the first 2 years of post-injury. However, some of the refluxes were transient and disappeared spontaneously without causing any damage to the upper urinary tract. Several patients with VU reflux were on external condom drainage when reflux was detected. Three of these patients were treated by inserting a Foley catheter to correct any obstructed outlet and to provide a free urinary drainage. We followed 27 patients with 38 refluxes treated with an indwelling Foley catheter. After 4 years of follow-up the number of refluxes increased and progressed to grade III and IV, causing kidney damage with caliectasis. Therefore, we agree 
with Fellows and Silver (1976) that a Foley catheter does not prevent refluxes from worsening and does not protect the upper tract from damage.

All patients on indwelling Foley catheter exhibited bacteriuria during the follow-up period. Asymptomatic bacteriuria was not treated with antibiotics. However, it is difficult to ascertain retrospectively whether all symptomatic episodes of urinary tract infection was treated properly with medications. Therefore, it is impossible to correlate urinary tract infections with the incidence and severity of renal damage in the refluxing kidney as implicated by other investigators (Roberts et al., 1982). We had 4 patients with VU refluxes that had a balanced bladder and were followed on external condom catheters. Because of the small number of patients with reflux and the shorter period of follow-up, it is statistically difficult to compare this group with the Foley catheter group.

VanArdalen and Hackler (1983) reported that reflux disappears in 52\% of their patients after external sphincterotomy. However, we had only one patient with VU reflux who had an external sphincterotomy for detrusor-sphincter dyssynergia and the follow-up period was only one year. The majority of our patients had a Foley catheter and some individuals were treated with intermittent catheterisation without sphincterotomy because they did not have dyssynergia. The majority of our patients with reflux had complete spinal lesions. This is the first report in the literature where the incidence of VU reflux is higher in SCI patients with complete spinal lesion than in those with incomplete neurological dysfunction. We do not have any explanation for this phenomenon. In addition, $62.5 \%$ of our patients who had reflux had upper motor neuron lesion. Therefore, we agree with Damanski (1965) that this incidence of reflux was higher in SCI patients with an upper motor neuron lesion. We did not perform urodynamics on every patient studied. Since the clinical neurological examination correlates well with bladder urethral dysfunction in SCI patients (Wyndaele, 1984), we may conclude that patients with an upper motor neuron bladder (UMNB) have a higher incidence of reflux formation.

\section{Conclusions}

We found that the incidence of reflux was higher in SCI patients with complete spinal lesion; quadriplegics had the same incidence of reflux as paraplegics; patients with an upper motor neuron lesion had a higher incidence of reflux formation; the indwelling Foley catheter did not prevent reflux formation; some of the refluxes were transient and disappeared spontaneously within 1-2 years of post-injury; after more than 4 years of follow-up, the Foley catheter did not prevent progression of reflux and did not protect the upper urinary tract from damage. Therefore, Foley catheter drainage as a long-term treatment for SCI patients should be avoided. This is also the case for suprapubic cystostomy.

\section{Acknowledgement}

The author wishes to express his appreciation to Richard Bourne, MD, Associate Professor of Urology, the Medical College of Wisconsin and to Jose F. Leyson, MD, Associate Professor of 
Urology, the University of New Jersey School of Medicine for reviewing the manuscript and for their suggestions.

\section{References}

DAMANSKI M 1965 Vesico-ureteric reflux in paraplegia. British fournal of Surgery 52:168-176. Fellows GJ, Silver JR 1976 Long-term follow-up paraplegics with vesicoureteral reflux. Paraplegia 14:130-134.

Fine PR, DeVivo MJ, Go BK, et al. 1985. The state of the National SCI Data Base. Proceedings of American Spinal Injury Association, Atlanta, Georgia pp. 20-24.

HACKLER RH 1982 Long-term suprapubic cystostomy drainage in spinal cord injury patients. British fournal of Urology 54:120-121.

INTERNATIONAL REFLUX STUDY COMMITTEE 1981 Medical versus surgical treatment of primary vesicoureteral reflux: A prospective international reflux study in children. Fournal of Urology 125:277-283.

KaSs EJ, KofF SA, Diokno AC 1981. Fate of vesicoureteral reflux in children with neuropathic bladder managed by intermittent catheterization. Fournal of Urology 125:63-64.

Roberts JA, Fischman NH, Thomas R 1982 Vesicoureteral reflux in the primate IV: Does reflux harm kidney. Fournal of Urology 128:650-652.

VANARSDALEN KN, HACKLER RN 1983 Transureteroureterostomy in spinal cord injury patients for persistent vesicoureteral reflux: 6 to 14 years follow-up. Fournal of Urology 129:1117-1119.

Woolf CM 1968 Principles of Biometry. Van Nostrand, Princeton, pp. 98-112.

WYNDAELE JJ 1984 A critical review of urodynamic investigations in spinal cord injury patients. Paraplegia 22:138-144. 